\title{
REGRESSION ANALYSIS FOR STATURE DETERMINATION FROM HAND ANTHROPOMETRY OF MALAYSIAN MALAYS FOR FORENSIC INVESTIGATION
}

\author{
T.Nataraja Moorthy ${ }^{1}$ and Nuranis Raihan Binti Zulkifly ${ }^{2}$ \\ ${ }^{1}$ Corresponding author and Associate Professor of Forensic Sciences, Dept. of Medical Specialty, Faculty \\ of Health and Life Sciences, Management and Science University,40100 Shah Alam, Selangor, Malaysia. \\ ${ }^{2}$ Forensic Science Program, Universiti Sains Malaysia, 16150 Health campus, Kubang Kerian, Kelantan, \\ Malaysia.
}

\begin{abstract}
During the investigation of mass disasters cases, the primary aim of any forensic investigator is to identify the individuals by analyzing the disintegrated human body organs. Stature determination has been shown as possible using the measurements of different body parts. Hand anthropometry is found to yield important predictive information about an individual's stature and may further help in narrowing down the possible matching identities. Literature review shows that a limited number of studies have been conducted on stature estimation from hand measurements. The present investigation is aimed to derive population specific regression equations to estimate stature from hand anthropometry of Malaysian Malays, since it is improper to utilize a single equation derived from a particular population for various populations.
\end{abstract}

\section{KEYWORDS:}

Forensic science, Forensic anthropology, Stature, Hand anthropometry, Malaysian Malays.

\section{INTRODUCTION}

Stature estimation has been shown as possible using the measurements of different body $\operatorname{parts}^{1-3}$.

"Stature provides insight into various features of a population including nutrition, health and genetics; geographical location, environment and climatic condition"4. Assessment of height from different body parts is an area of interest to anatomists, anthropologists and to forensic experts ${ }^{5}$. It is generally accepted that the most accurate biological profile is formulated using contemporary population specific standards ${ }^{6}$. Several studies were conducted to estimate stature from dimensions of hands, handprints ${ }^{6}$, feet and footprints ${ }^{7}$ in the past, and derived regression equations to estimate stature from these variables for person identification. There are no population specific formulae for stature determination from hands in a Malaysian Malay population. Hence, the aim of the present investigation is to derive population specific regression equations to determine stature from hand anthropometry in Malaysian Malays. 


\section{MATERIALS AND METHODS}

\section{Materials}

Participants that included 100 male and 100 female Malaysian Malays were of age ranging from 18 to 60 years. Malays are an ethnic group who predominantly inhabit the Malay Peninsula, the east coast of Sumatra and the coast of Borneo and who speak a MalayoPolynesian language, which is a member of the Austronesian family ${ }^{8}$. The participants were confirmed to be descent from three generations of Malays to ensure no genetic variation within races that can disrupt the results as characteristics of hand measurements can be affected by not only environment but also genetic makeup? Information such as name of subject and place of origin was recorded. Informed consent was obtained from all participants, and followed the procedures in accordance with the ethical standards of University Research Ethics Committee (Human). A total of 400 bilateral hand measurements were obtained from Malaysian Malay participants. All the participants included in the study were healthy and free from any apparent symptomatic deformity of the hand.

\section{Methods}

"Stature was measured without head and footwear using a portable body meter measuring device (SECA model 208). The body meter was suspended upright against the wall and measurements were taken to the nearest $0.5 \mathrm{~cm}$. The subject was advised to stand under the body meter with his heels together and weight evenly distributed between both feet. Stature was measured in $\mathrm{cm}$ as the vertical distance between the vertex and the sole of the foot when the individual was standing barefoot with head held in the Frankfurt horizontal plane with eyes looking forward. Following the previous research, the measurements were repeated until concordant values achieved" $"$. Considering the diurnal variation, all the measurements were taken at a fixed time in the afternoon. "The diurnal change in height of a person was indicated as early as 1726 and the shortening in stature during daytime was reported and confirmed by the researchers"11-12. Seven anthropometric measurements were taken on each individual using a $250 \mathrm{~mm}$ digital sliding caliper (Mitutoyo CD67-S20PS). "The hand of the subject was placed on the flat hard horizontal surface with the thumb in abducted position and other fingers in extended position" ${ }^{\prime 3}$. "The hand length is the linear distance between the point inter-stylion and the most anterior projection of the middle finger" ${ }^{13}$. " The hand breadth is the linear distance between the radial side of the second metacarpophalyngeal joint and the ulnar side of the fifth metacarpophalyngeal joint"13. "The finger length (thumb, Index, middle, ring and little fingers) is the distance between the proximal flexion crease of the finger to the tip of the respective finger", ${ }^{\prime, 14-15}$ (Fig 1). The measurements on the subjects were made by the same researcher ${ }^{13}$. The data obtained were computed and analyzed with SPSS (Statistical Package for Social Sciences, Version 20.0) computer software.

\section{RESULTS}

Descriptive statistics of stature measurements in males, females are shown in Table 1. In males, the stature ranges from 157.0 to 184.0 $\mathrm{cm}$ (mean $168.7 \mathrm{~cm}$ ) and in females it ranges from 142.0 to $168.0 \mathrm{~cm}$ (mean $156.3 \mathrm{~cm}$ ). The result showed that the mean stature is found to be significantly higher in males than females.

Tables 2 and 3 show the statistical data of the hand dimensions in the female and male of Malaysian Malay population. The mean values of the male hand dimensions were 
higher than those of the female hand dimensions, and the differences in the hand dimensions between the males and the females were statistically significant $(p<0.05)$ in the population (Fig 2). Sex differences were significant for all measurements. It is readily apparent that there appears to be very little bilateral variation in the hand dimensions in both sexes. The mean left hand length of male is found to be slightly longer than the right. But the finding is opposite in female hand length measurements.

Table 4 presents the correlation coefficient (R) between stature and various hand and finger length measurements and are found statistically significant $(<0.001)$. Correlation coefficient values are found to be more in females (0.630-0.673) than males (0.0410.610) hand length measurements. The correlation coefficient between stature and hand lengths is found to be higher than hand breadth and finger length measurements.

Table 5 and 6 present the linear regression equations derived from the stature and bilateral hand dimensions in both sexes. Standard error of estimate (SEE) shown in the tables indicated that SEE of hand length is comparatively lower than hand breadth and finger lengths in both genders.

\section{DISCUSSIONS}

The mean value of male stature is comparatively higher than that of female stature in this population, and this finding is in accordance with other population results showing that males are taller than females ${ }^{4-}$ 7,10,13-16. "Small differences exist in the mean value of stature of both sexes between the present study and other studies" because of population variation. The differences in the bilateral hand dimensions are not statistically significant in this population. "The hand length showed a higher correlation coefficient for stature than the hand breadth in both sexes, and the similar findings were observed in the previous studies"3,13,15-16. The findings of the present and previous studies indicated that a more accurate stature could be estimated based on hand length than hand breadth. The left hand length shows higher correlation coefficient while right hand breadth shows higher correlation in both genders of this population but some studies have reported different results ${ }^{3,13-16}$. The regression equations derived from hand dimensions of Malaysian Malay population are different from other populations $3,4-6,13-16$, and so do the correlation coefficients showing population variation. In assessing the accuracy of simple linear regression models in Malaysian Malays, the standard error of the estimate (SEE) was comparatively lower using the measurement of hand length (SEE 4.465-4.757 cm). Expectedly, other population studies have indicated that this is the most accurate measurement for estimating stature, albeit their regression models have a higher stated accuracy: eg. North Indian population ${ }^{5}$ (3.78$5.22 \mathrm{~cm}$ ); Western Australian population ${ }^{6}$ (SEE 4.74-5.17 cm); Hans population of Southern China ${ }^{13}(5.05-5.64 \mathrm{~cm})$; Egyptian population $^{14}(4.54-5.48 \mathrm{~cm})$; Indian medical students ${ }^{15}(4.23-4.96 \mathrm{~cm})$; north and south Indian population ${ }^{16}(3.65-5.04 \mathrm{~cm})$. Thus the variations in hand dimensions may be attributed to the population and ethnic differences.

\section{CONCLUSION}

It is concluded that hand dimensions can provide good reliability in stature determination. The present study developed regression equations for stature determination from various hand measurements in a Malaysian Malay population. Similar stature- 
hand research may be continued to investigate and derive relevant regression equations to determine stature from hand anthropometry for other populations living in different parts of the world.

\section{CONFLICT OF INTEREST}

The authors have no conflict of interest to declare.

\section{ACKNOWLEDGMENT}

The authors are thankful to the participants who took part in the study. The authors did not receive any specific funding for the aforementioned research.

Table 1: Descriptive statistics of stature in males and females of adult Malaysian Malays.

\begin{tabular}{|l|l|l|l|l|l|}
\hline Sex & N & Min $(\mathrm{cm})$ & Max $(\mathrm{cm})$ & Mean $(\mathrm{cm})$ & SD \\
\hline Male & 100 & 157.0 & 184.0 & 168.7 & 0.6 \\
\hline Female & 100 & 142.0 & 168.0 & 156.3 & 0.6 \\
\hline
\end{tabular}

N: Number of participant; Min: Minimum; Max: Maximum; SD: Standard deviation

Table 2: Descriptive statistics of right and left hand measurements of Malaysian Malay females (in cm)

\begin{tabular}{|c|c|c|c|c|c|c|c|c|c|}
\hline \multirow{2}{*}{ Measurement } & \multirow{2}{*}{$\mathrm{N}$} & \multicolumn{5}{|c|}{ Right side } & \multicolumn{4}{c|}{ Left side } \\
\cline { 3 - 11 } & & Min & Max & Mean & SD & Min & Max & Mean & SD \\
\hline Hand length & 100 & 15.0 & 19.8 & 17.0 & 0.9 & 15.1 & 19.7 & 16.9 & 0.8 \\
\hline Hand breadth & 100 & 5.8 & 8.2 & 7.0 & 0.5 & 5.9 & 7.8 & 6.9 & 0.4 \\
\hline Thumbs finger & 100 & 4.9 & 7.2 & 5.8 & 0.5 & 4.2 & 7.0 & 5.8 & 0.4 \\
\hline Index finger & 100 & 5.4 & 7.7 & 6.6 & 0.4 & 5.2 & 7.8 & 6.6 & 0.4 \\
\hline Middle finger & 100 & 6.3 & 8.5 & 7.2 & 0.4 & 6.3 & 8.5 & 7.2 & 0.4 \\
\hline Ring finger & 100 & 5.7 & 8.0 & 6.7 & 0.4 & 5.9 & 7.9 & 6.7 & 0.4 \\
\hline Little finger & 100 & 4.7 & 6.4 & 5.4 & 0.4 & 4.3 & 6.4 & 5.4 & 0.4 \\
\hline
\end{tabular}

N: Number of participants; Min: Minimum; Max: Maximum; SD: Standard deviation; 
Table 3: Descriptive statistics of right and left hand measurements of Malaysian Malay males (in cm)

\begin{tabular}{|l|c|l|l|l|l|l|l|l|l|}
\hline Measurement & \multirow{2}{*}{$\mathrm{N}$} & \multicolumn{3}{|l|}{ Right side } & \multicolumn{2}{l|}{ Left side } \\
\cline { 3 - 10 } & & Min & Max & Mean & SD & Min & Max & Mean & SD \\
\hline Hand length & 100 & 17.1 & 20.9 & 18.6 & 0.9 & 17.2 & 21.6 & 18.7 & 0.9 \\
\hline Hand breadth & 100 & 7.0 & 9.1 & 7.9 & 0.4 & 6.8 & 9.1 & 7.8 & 0.4 \\
\hline $\begin{array}{l}\text { Thumbs } \\
\text { finger }\end{array}$ & 100 & 5.4 & 7.7 & 6.4 & 0.5 & 5.4 & 7.7 & 6.5 & 0.5 \\
\hline Index finger & 100 & 5.9 & 8.3 & 7.2 & 0.5 & 6.1 & 8.5 & 7.2 & 0.5 \\
\hline $\begin{array}{l}\text { Middle } \\
\text { finger }\end{array}$ & 100 & 6.8 & 9.3 & 7.8 & 0.5 & 7.0 & 9.5 & 7.9 & 0.5 \\
\hline Ring finger & 100 & 6.3 & 8.7 & 7.3 & 0.5 & 6.4 & 8.7 & 7.3 & 0.5 \\
\hline Little finger & 100 & 5.0 & 7.0 & 5.9 & 0.4 & 5.0 & 7.4 & 5.9 & 0.4 \\
\hline
\end{tabular}

Table 4: Pearson correlation coefficient $(R)$ between stature and right and left hand measurements of male and female Malaysian Malays

\begin{tabular}{|l|c|c|c|c|}
\hline \multirow{2}{*}{ Hand measurements } & \multicolumn{2}{|c|}{$\mathrm{R}$ (male) } & \multicolumn{2}{c|}{$\mathrm{R}$ (female) } \\
\cline { 2 - 5 } & Right side & Left side & Right side & Left side \\
\hline Hand length & 0.604 & 0.610 & 0.630 & 0.673 \\
\hline Hand breadth & 0.424 & 0.390 & 0.230 & 0.173 \\
\hline Thumb length & 0.444 & 0.363 & 0.460 & 0.396 \\
\hline Index finger length & 0.448 & 0.458 & 0.537 & 0.567 \\
\hline Middle finger length & 0.494 & 0.492 & 0.528 & 0.533 \\
\hline Ring finger length & 0.436 & 0.465 & 0.469 & 0.541 \\
\hline Little finger length & 0.464 & 0.396 & 0.413 & 0.472 \\
\hline
\end{tabular}


Table 5: Linear regression equations for stature determination from male hand measurements of Malaysian Malays (in cm)

\begin{tabular}{|c|c|c|c|c|}
\hline \multirow[t]{2}{*}{ Hand Measurement } & \multicolumn{2}{|l|}{ Male right side } & \multicolumn{2}{|l|}{ Male left side } \\
\hline & Equations & SEE & Equation & SEE \\
\hline Hand length & $\mathrm{S}=94.399+4.005 \mathrm{HL}$ & 4.757 & $\mathrm{~S}=92.156+4.092 \mathrm{HL}$ & 4.729 \\
\hline Hand breadth & $\mathrm{S}=123.729+5.696 \mathrm{HB}$ & 5.406 & $\mathrm{~S}=127.053+5.322 \mathrm{HB}$ & 5.496 \\
\hline Thumb length & $S=132.659+5.615 T F L$ & 5.348 & $\mathrm{~S}=139.283+4.543 \mathrm{TFL}$ & 5.561 \\
\hline Index finger length & $\mathrm{S}=128.658+5.597 \mathrm{IFL}$ & 5.336 & $\mathrm{~S}=126.352+5.904 \mathrm{IFL}$ & 4.976 \\
\hline Middle finger length & $\mathrm{S}=123.211+5.805 \mathrm{MFL}$ & 5.191 & $\mathrm{~S}=121.077+6.067 \mathrm{MFL}$ & 5.198 \\
\hline Ring finger length & $\mathrm{S}=129.702+5.353 \mathrm{RFL}$ & 5.372 & $\mathrm{~S}=126.469+5.801 \mathrm{RFL}$ & 5.284 \\
\hline Little finger length & $S=132.100+6.172 \mathrm{LFL}$ & 5.286 & $\mathrm{~S}=134.744+5.803 \mathrm{LFL}$ & 5.480 \\
\hline
\end{tabular}

S: Stature; SEE: Standard error of estimate; HL: Hand length; Hand breadth; TFL: Thumb length; IFL: index finger length; MFL: Middle finger length; RFL: Ring finger length; LFLL Little finger length.

Table 6: Linear regression equations for stature determination from female hand measurements of Malaysian Malays (in cm)

\begin{tabular}{|l|l|c|c|c|}
\hline \multirow{2}{*}{ Hand measurement } & \multicolumn{2}{|l|}{ Female right hand } & \multicolumn{2}{l|}{ Female left hand } \\
\cline { 2 - 5 } & \multicolumn{1}{|c|}{ Equations } & SEE & Equation & SEE \\
\hline Hand length & $\mathrm{S}=81.423+4.415 \mathrm{HL}$ & 4.690 & $\mathrm{~S}=75.897+4.765 \mathrm{HL}$ & 4.465 \\
\hline Hand breadth & $\mathrm{S}=136.813+2.784 \mathrm{HB}$ & 5.878 & $\mathrm{~S}=139.478+2.428 \mathrm{HB}$ & 5.449 \\
\hline Thumb length & $\mathrm{S}=121.244+6.016 \mathrm{TFL}$ & 5.363 & $\mathrm{~S}=124.402+5.503 \mathrm{TFL}$ & 5.546 \\
\hline Index finger length & $\mathrm{S}=103.637+7.947 \mathrm{IFL}$ & 5.095 & $\mathrm{~S}=104.127+7.848 \mathrm{IFL}$ & 4.976 \\
\hline Middle finger length & $\mathrm{S}=101.431+7.581 \mathrm{MFL}$ & 5.128 & $\mathrm{~S}=103.110+7.376 \mathrm{MFL}$ & 5.110 \\
\hline Ring finger length & $\mathrm{S}=111.690+6.668 \mathrm{RFL}$ & 5.335 & $\mathrm{~S}=101.281+8.237 \mathrm{RFL}$ & 5.080 \\
\hline Little finger length & $\mathrm{S}=118.443+6.992 \mathrm{LFL}$ & 5.502 & $\mathrm{~S}=116.396+7.457 \mathrm{LFL}$ & 5.324 \\
\hline
\end{tabular}

S: Stature; SEE: Standard error of estimate; HL: Hand length; Hand breadth; TFL: Thumb length; IFL: Index finger length; MFL: Middle finger length; RFL: Ring finger length; LFL: Little finger length. 


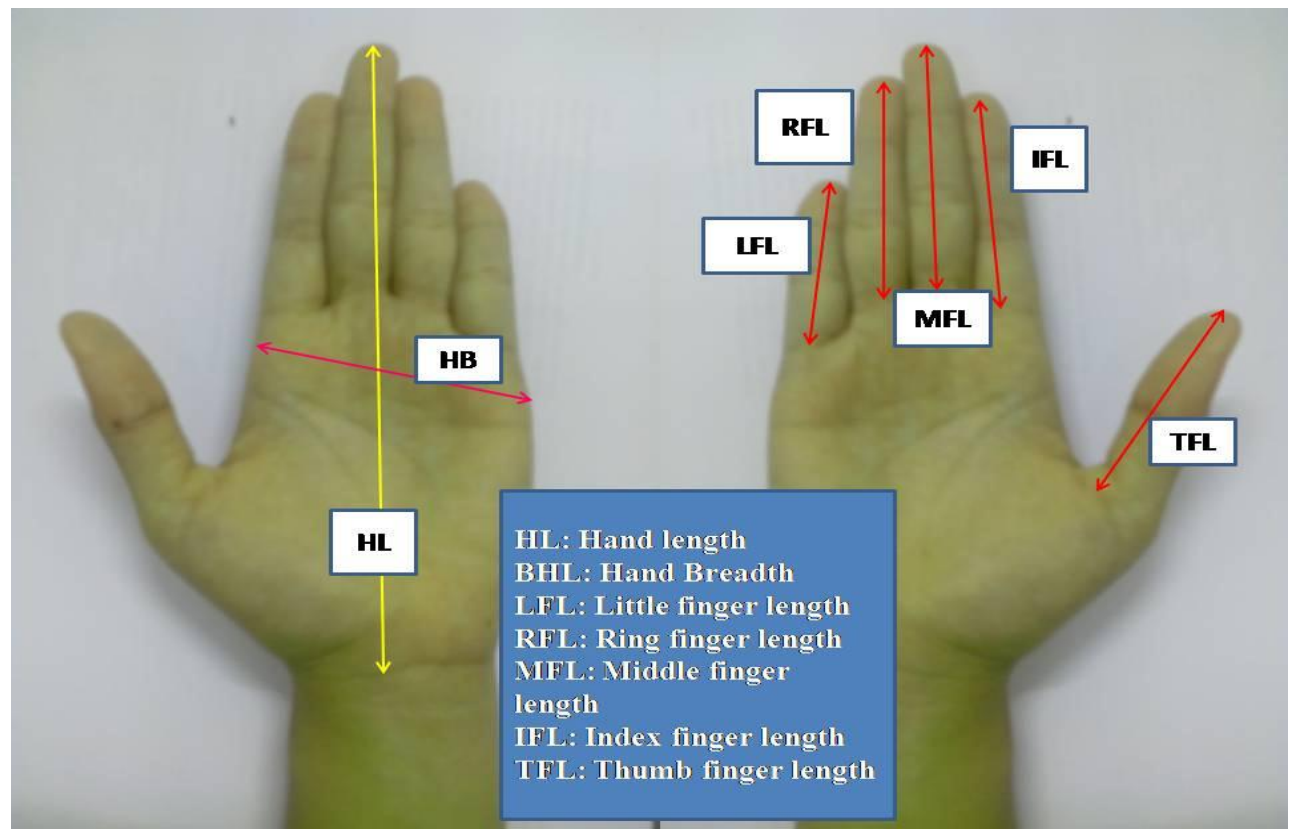

Figure 1: Various hand and finger measurements

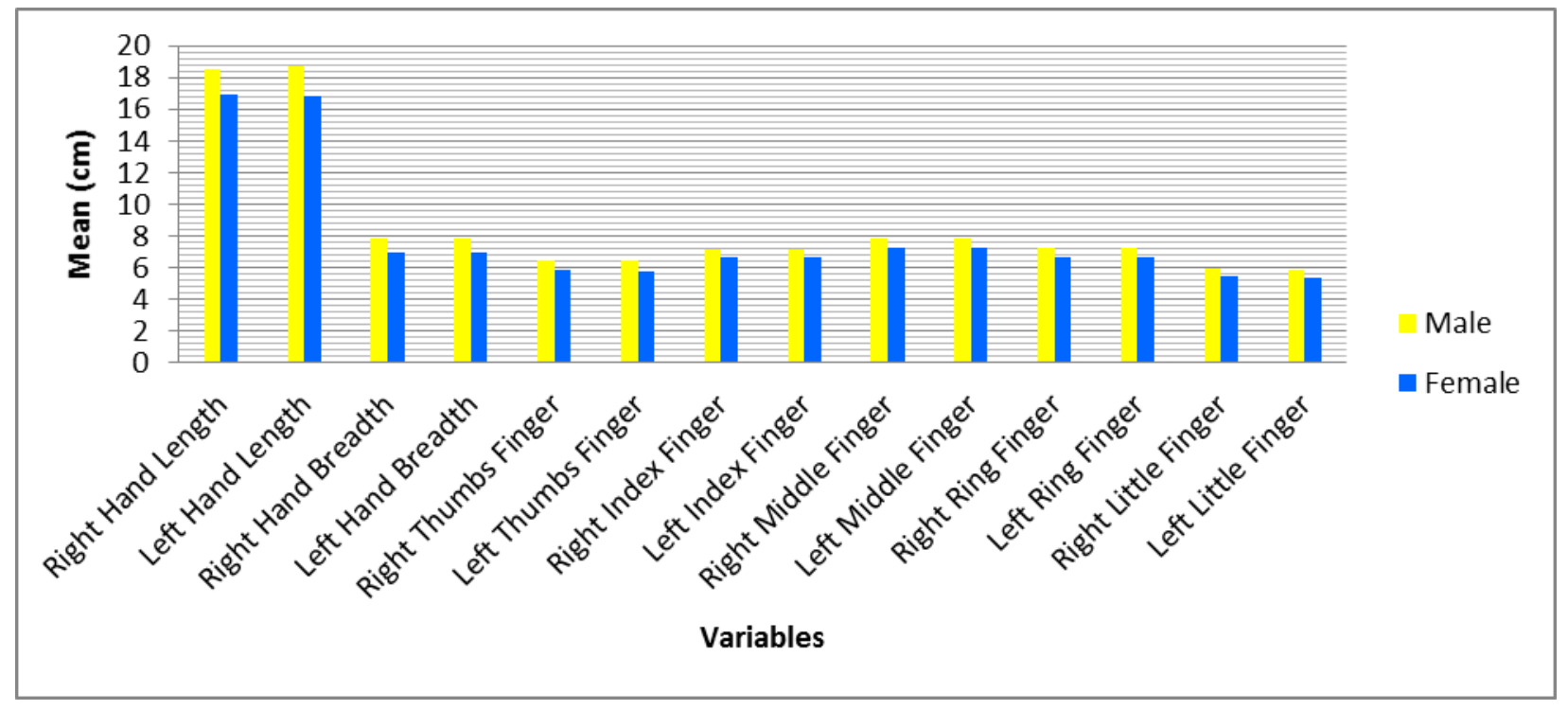

Figure 2: Bar chart showing gender variation among hand measurements of Malaysian Malays 


\section{REFERENCES}

1. Ozaslan A, Iscan MY, Ozaslan I, Tugcu H, Koc S.Estimationon of stature from body parts. Forensic Science Interntional 2003; 132 (1):40-45.

2. Zverev YP. Relationship between arm span and stture in Malawian adults. Annals of Human Biology 2003; 30 (6): 739-743.

3. Salini SG, Kizilkanat ED, Boyan N, Ozsahin ET, Bozkir MG, Soames R, Erol H, Oguz O. Stature estimation based on hand length and foot length. Clinical Anatomy 2005; 18 (8): 589-596.

4. Jothi A, Leena R, Sushma K, Surbhi R. Estimation of stature from hand length and length

of phalanges. Journal of Evolution of Medical and Dental Sciences 2013; 12 (50): 9651-6.

5. Krishan K, Sharma A. Estimation of stature from dimensions of hands and feet in a north Indian population. Journal of Forensic and Legal Medicine 2007; 14: 327-32.

6. Nur-Intaniah I, Naomi H, Daniel F. Estimation of stature from hand and handprint dimensions in a western Australian population. Forensic Science International 2012; 199: e1-e7.

7. Nataraja Moorthy T, Ahmad M, Boominathan R, Raman N. Stature estimation from footprint measurements in Indian Tamils by regression analysis. Egyptian Journal of Forensic Sciences 2014; 4: 7-16.

8. Hatin WI, Nur-Shafawati AR, Zahri M-K, Xu S, Jin L, et al. Population genetic structure of Peninsular Malaysia Malay sub-ethnic groups. PLoS One 2011; 6 (4):e18312. http://dx.doi.org/ 10.1371/ journal.pone.0018312.
9. Nataraja Moorthy $\mathrm{T}$, Siti Fatimah $\mathrm{S}$. Individualizing characteristics of footprints in Malaysian Malays for person identification in forensic perspective. Egyptian Journal of Forensic Sciences 2015; 5: 13-22.

10. Nataraja Moorthy $T$, Ang Yan L, Saufee Affandi S, Nik Fakhuruddin N. Estimation of stature from footprint and foot outline measurements in Malaysian Chinese. Australian Journal of Forensic Sciences 2014; 46 (2): 136-59.

11. Whitehouse RH, Tanner JM, Healy MJ. Diurnal variation in stature and sitting height in 12-14year-old boys. Annals of Human Biology 1974;1:103-6.

12. Krishan K, Vij K. Diurnal variation of stature in three adults and one child. Anthropologist 2007; 9:113-7.

13. Tang J, Chen R, Lai X. Stature estimation from hand dimensions in Han population of Southern China. Journal of Forensic Sciences 2012; 57: 1541-44.

14. Sahar Refaat H, Nashwa Nabil K. Stature estimation from hand and phalanges lengths of Egyptians. Journal of forensic and Legal Medicine 2010; 17(3): 156-60.

15. Agnihotri S Agnihotri N, Jeebun K. Googoolye. Prediction of stature using hand dimensions. Journal of Forensic and Legal Medicine 2008; 15:479-82.

16. Rastogi P, Nagesh KR, Yoganarasimha K, Estimation of stature from hand dimensions of North and South Indians. Legal Medicine 2008; 10 (4):185-9. 